\title{
NUMERICAL ANALYSIS OF THE IMPACT OF SIDESLIP ANGLE ON LOAD OF THE GYROCOPTER STABILIZERS
}

\author{
Zbigniew CZYŻ (1) ${ }^{1^{*}}$, Paweł KARPIŃSKI ${ }^{2}$ \\ ${ }^{1}$ Aeronautics Faculty, Polish Air Force University, 35 Dywizjonu 303 St., 08-521 Dęblin, Poland \\ ${ }^{2}$ Department of Thermodynamics, Fluid Mechanics and Aviation Propulsion Systems, Faculty of Mechanical \\ Engineering, Lublin University of Technology, 36 Nadbystrzycka St., 20-618 Lublin, Poland
}

Received 25 April 2019; accepted 13 January 2020

\begin{abstract}
The paper presents some of the works related to the project of modern gyrocopter construction with the possibility of a short start, known as "jump-start". It also presents a methodology related to numerical calculations using Computational Fluid Dynamics based on ANSYS Fluent three-dimensional solver. The purpose of the work was to calculate the forces and aerodynamic moments acting on the gyrocopter stabilizers. The calculations were carried out for a range of angle of attack $\alpha$ from $-20^{\circ}$ to $+25^{\circ}$ and for a sideslip angle $\beta$ from $0^{\circ}$ to $20^{\circ}$. Based on the calculations carried out, analysis of the impact of the slip angle on the load on the stabilizers has been made.
\end{abstract}

Keywords: aerodynamic force, autogyro, gyrocopter, gyroplane, sideslip angle, stabilizer.

\section{Introduction}

Gyroplanes are light aircraft, which in recent years have become increasingly popular in general aviation. They are used for passenger transport, for monitoring large areas by state services and recreational aviation. Martin (2014) presented an analysis of the benefits of using gyroplanes in police aviation operational activities. In comparison to light helicopters, gyroplanes have a smaller mass, simpler structure and do not require a countering torque system (Leishman, 2006). In recent years, numerous studies have been carried out on unmanned gyroplanes (Jensen, 2001; Xiang et al., 2014; Ma et al., 2015; Zhang et al., 2014). The growing popularity of gyroplanes encourages the modernization and optimization of existing structures. Stalewski (2017) presented in his work a performance analysis of light gyroplane using computational methods of Computational Fluid Dynamics, Flight Dynamics, Computer Aided Design and Optimization. In the work Anh Vu et al. (2011), the method of optimization of compound gyroplane geometry was presented, in which existing aircraft data was used. In recent years, many papers have been published devoted to the dynamics of the gyroplane flight and control analysis. An example is the work of Cheng et al. (2016), in which the modeling of gyroplane has been presented. Another example is the publication Lin, Cai, and Wang (2014), which presents a control model for a small unmanned gyroplane. A fly-to-trim method was used to trim the aircraft. In order to optimize the structure of the aircraft, numerical methods come in handy to allow a quick and low-cost carrying out of a number of tests. An example of such a method is Computational Fluid Dynamics (CFD), which is used to analyze the aerodynamic forces generated on individual parts of the aircraft. As a result of numerical calculations, the values of aerodynamic forces and moments as well as velocity and pressure distribution around the tested element are obtained. An example of research in which this method was used is the work of Patel et al. (2014), in which the lift force and the drag force for the selected NACA air profile were obtained. Green and Findlay (2016) in his work, using the CFD method, studied the forces and aerodynamic moments generated on the hull carrier-based multirole fighter. Similar research was carried out by Dziubiński, Jaśkowiski, and Seredyn (2016), who developed aerodynamic characteristics for agricultural aircraft in an operational range of the angle of attack and the sideslip angle. The CFD method was also used by Della Vecchia, Nicolosi, and Ciliberti (2015), who investigated the aerodynamic interference for selected aircraft components. For the considered parts of the research object, yawing moment coefficients were determined for

${ }^{*}$ Corresponding author. E-mail: $z . c z y z @ l a w . m i l . p l$ 
directional stability analysis of the aircraft. The analysis of the flow around the gyroplane fuselage, including aerodynamic forces generated on individual elements, was investigated by Czyż et al. (2017).

Simulation tests of the aircraft can be verified by conducting tests in the wind tunnel. Krzysiak (2017) using the PIV method (Particle Image Velocimetry) in the wind tunnel investigated the quad-rotor autogyro model. Obtained basic aerodynamic properties as well as flow visualization of the tested object. The tests showed the flow induced by the main rotor changing the autogyro aerodynamic characteristics.

Tail unit is a key element of an aircraft because it is responsible for vertical and horizontal flight stability. Many mathematical models were created describing the stability of gyroplanes. An example is the work of Wang and $\mathrm{Li}$ (2014), in which the nonlinear mathematical model of autogyro longitudinal stability was presented and the effects of the wing on autogyro longitudinal stability were examined. Houston and Thomson (2017) describes the modeling of gyroplane flight mechanics with attention to modeling requirements for simulation stability and control analysis. The longitudinal and lateral stability of the gyroplane was also examined by Houston $(1996,1998)$. The impact of the rotor on the stability of the gyroplane using the CFD method was investigated by Figat (2017). This method was also used by Xiang et al. (2015) to perform simulation calculations of the aerodynamics of a gyrocopter rotor.

Another problem is the analysis of aerodynamic forces generated at the tail unit. Houston (2011) in his work investigated factors influencing horizontal stabiliser effectiveness with particular emphasis on dynamic stability. The aim of this study was to analyze the aerodynamic forces created on the horizontal and vertical tail of the gyroplane model examined, depending on the angle of attack and the sideslip angle. This work is a continuation of research performed in the works of Czyż et al. (2017), Czyż et al. (2018). The Czyż et al. (2017) publication analyzed the impact of individual gyrocopter components such as fuselage and particular elements of tail unit on the value of aerodynamic forces and moments as a function of the angle of attack. In the article Czyż et al. (2018), based on the obtained results and the assumed stability criterion, a static analysis of the longitudinal stability of the gyroplane under test for different angles of the horizontal stabilizer was made. Interference of the rotor with the wing for compound gyroplane using fast method of aerodynamic computation (FMAC) was investigated by Ma et al. (2015).

\section{Research object}

The research object was a gyrocopter model with a wheeled landing-gear in a classic configuration without a main rotor. The solid model was developed in the CATIA V5 program. In order to analyze the aerodynamic forces affecting the tail unit of the test object, the horizontal and vertical stabilizers were distinguished.
The dimensions of the gyrocopter model under study are $6348 \times 2780 \times 3148 \mathrm{~mm}$ (length $\mathrm{x}$ width $\mathrm{x}$ height). The global clockwise Cartesian coordinate system was used to describe the position of the gyroplane. The angle of attack $\alpha$ and the sideslip angle $\beta$ were measured as shown in Figure 1.

Numerical calculations of the gyrocopter model were carried out in the Ansys Fluent software. In the Design Modeler module, discontinuities and sharp edges from the geometry of the tested aircraft have been removed. The model was placed within the computational domain with the dimensions indicated in Figure 2. The velocity and pressure outlet were set on the domain surface. The surface of the gyroplane with the surfaces of stabilizers was set as a wall type.

The simulation was based on pressure based calculations. The k- $\omega$ SST model taking into account the kinetic energy of turbulence and the unitary dissipation of kinetic energy was assumed as the turbulence model. The limitations of main stresses in the flow have been taken into

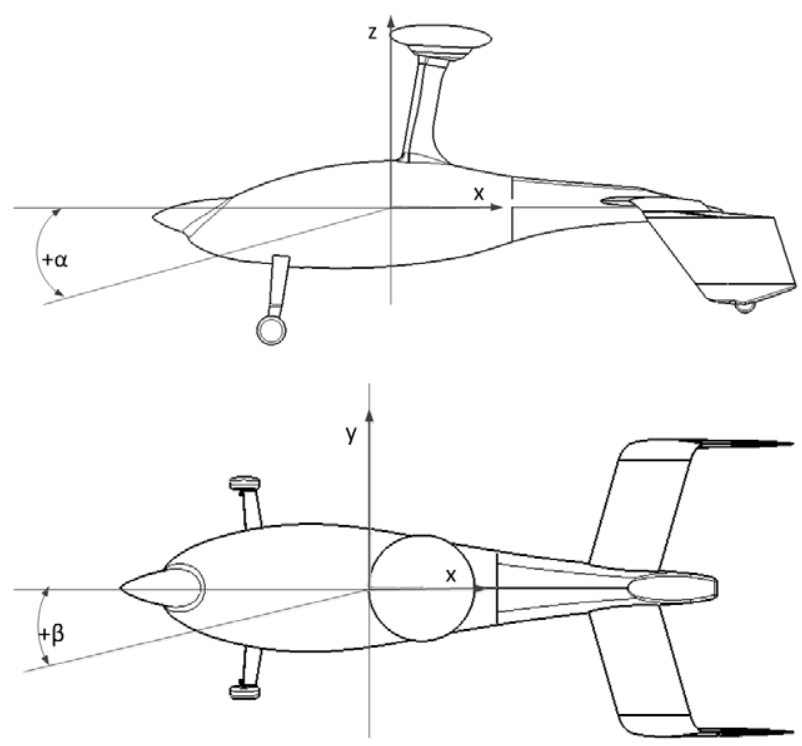

Figure 1. Gyrocopter model with highlighted angle of attack $\alpha$ and sideslip angle $\beta$

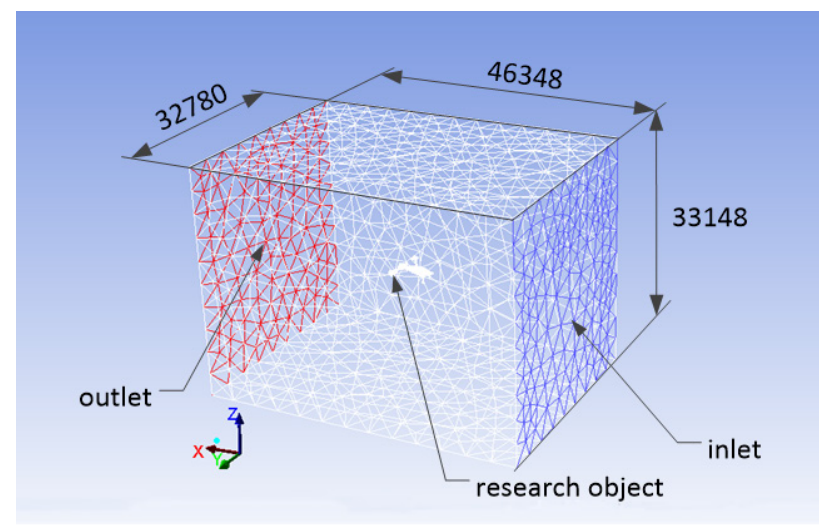

Figure 2. Computational domain with highlighted inlet and outlet 
account in the turbulence model. The calculations were made with the assumed turbulence intensity level and the turbulence viscosity ratio as a boundary conditions at the inlet and outlet. Their values were equal to $1 \%$ and 5 , respectively. The calculations were carried out for an air flow equal to $28 \mathrm{~m} / \mathrm{s}$. The defined gas parameters were summarized in Table 1.

Table 1. Selected parameters of the assumed gas

\begin{tabular}{|c|c|}
\hline Gas & Air \\
\hline Type & Ideal gas \\
\hline Temperature & $288 \mathrm{~K}$ \\
\hline Viscosity & $1.7894 \cdot 10^{-5} \mathrm{~kg} /(\mathrm{ms})$ \\
\hline
\end{tabular}

The work concerns the study of the influence of the sideslip angle on the tail unit load. Therefore, only the elements indicated in Figure 3 were considered for the analysis. All calculations were performed for the determined aircraft geometry, which means that the results of the aerodynamic forces acting on individual parts of the tail unit take into account the impact of the fuselage. Forces and aerodynamic moments were read separately on the left and right stabilizers, including the vertical and horizontal parts. General characteristics of the considered gyroplane are presented in the work Czyż et al. (2017).

The model grid was created in the Meshing module. Elements of the tetrahedrons type with the Curvature size function were used with the maximum value of the skewness equal 0.91 . In addition, a boundary layer was created near the surface of the gyroplane model using the Inflation function with the Smooth Transition function. As a result, a grid of 6.7 million elements was obtained. Figures 4-7 shows the grid for the entire model and the grid on the tested surfaces of vertical and horizontal stabilizers.

For the created model, tests of aerodynamic forces generated on gyrocopter stabilizers for assumed angles of attack and sideslip angles were performed. The angle of attack was changed in the range $-20^{\circ}$ to $+25^{\circ}$, every $5^{\circ}$, and the sideslip angle changed in the range of $0^{\circ}$ to $+20^{\circ}$, every $5^{\circ}$.

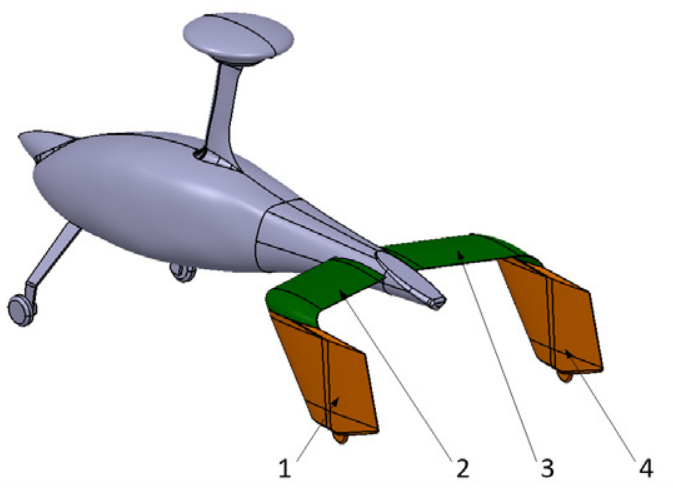

Figure 3. Gyrocopter model with highlighted vertical stabilizers ( 1 and 4 ) and horizontal stabilizers (2 and 3)

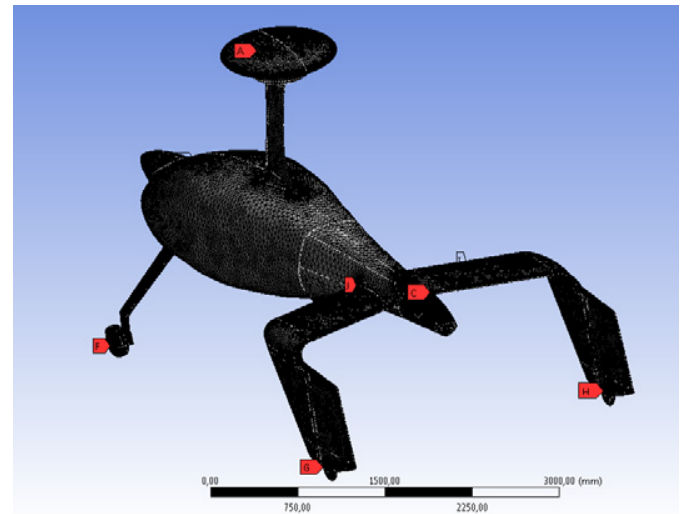

Figure 4. View of the computational grid on the surface of the gyrocopter, including the tail unit, mast and landing-gear

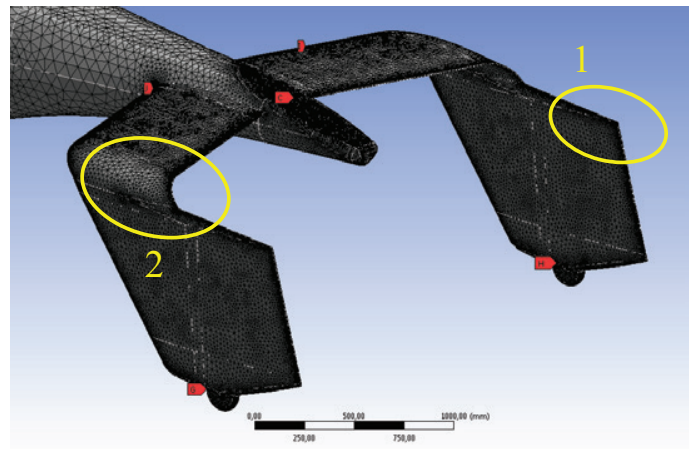

Figure 5. Generated mesh for the stabilizers

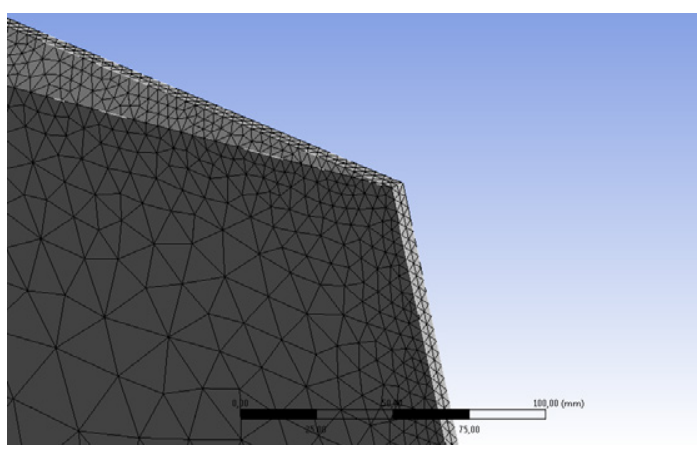

Figure 6. Detailed view of the grid in area 1 indicated in the previous figure

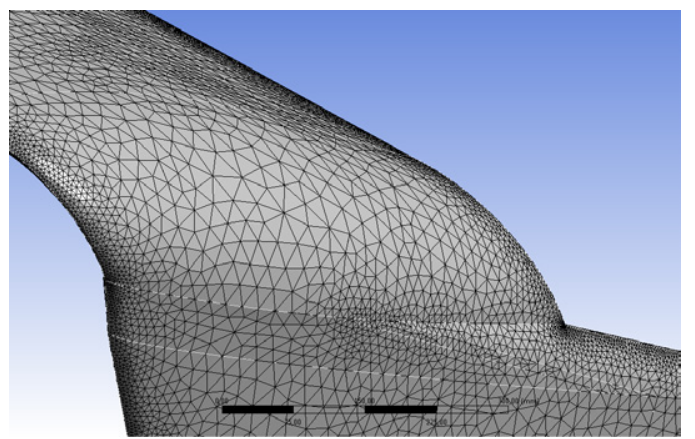

Figure 7. Detailed view of the grid in area 2 indicated in the Figure 5 


\section{Results and discussion}

As a result of the calculations carried out, the values of aerodynamic force components were obtained: $P_{x}$ drag forces, $P_{y}$ side force and $P_{z}$ lift forces generated on individual stabilizers for the considered range of angles of attack $\alpha$ and sideslip angles $\beta$. Due to the volume of the results obtained (50 tables with values of aerodynamic forces), it was decided not include them in this work. Only sample results for $\alpha=25^{\circ}$ and $\beta=0^{\circ}$ and $\beta=20^{\circ}$ are shown in Table 2 and 3.

After summing the components of a given force for all the stabilizers, the total value of the given aerodynamic force acting on the tail was obtained. On the basis of the determined values of the forces, the corresponding aerodynamic coefficients were calculated using the formula:

$$
C_{x, y, z}=\frac{P_{x, y, z}}{0.5 \rho v^{2} \pi R^{2}} .
$$

To calculate the coefficients, an aircraft rotor radius of $R=5 \mathrm{~m}$ was assumed, air density $\rho=1.226 \mathrm{~kg} / \mathrm{m}^{3}$ and air velocity $v=28 \mathrm{~m} / \mathrm{s}$.

Figure 8 shows the value of the drag coefficient for stabilizers as a function of the angle of attack for the values of the sideslip angle considered. For a given sideslip angle together with the increase of the angle of attack (counting from $\alpha=-20^{\circ}$ ), the value of the drag coefficient decreases, reaching the minimum around $\alpha=0^{\circ}$. Further increase in the angle of attack results in an increase in the $C_{x}$ coefficient. Increasing the sideslip angle results in an increase in the value of the drag coefficient over the entire range of attack angles. For the sideslip angle equal to $\beta=20^{\circ}$ and

Table 2. Calculated aerodynamic forces for stabilizers for $\alpha=25^{\circ}$ and $\beta=0^{\circ}$

\begin{tabular}{|l|c|c|c|}
\hline \multirow{2}{*}{\multicolumn{1}{|c|}{ Name of element }} & \multicolumn{3}{|c|}{ Aerodynamic force, $\mathrm{N}$} \\
\cline { 2 - 4 } & $P_{x}$ & $P_{y}$ & $P_{z}$ \\
\hline Vertical stabilizer left & 3.52 & -132.63 & -0.78 \\
\hline Vertical stabilizer right & 3.72 & 131.44 & -0.72 \\
\hline Horizontal stabilizer left & 156.92 & -24.62 & 307.36 \\
\hline Horizontal stabilizer right & 157.31 & 24.26 & 306.99 \\
\hline Total & 321.46 & -1.55 & 612.85 \\
\hline
\end{tabular}

Table 3. Calculated aerodynamic forces for stabilizers for $\alpha=25^{\circ}$ and $\beta=20^{\circ}$

\begin{tabular}{|l|c|c|c|}
\hline \multirow{2}{*}{\multicolumn{1}{|c|}{ Name of element }} & \multicolumn{4}{|c|}{ Aerodynamic force, N } \\
\cline { 2 - 4 } & $P_{x}$ & $P_{y}$ & $P_{z}$ \\
\hline Vertical stabilizer left & 76.98 & 226.59 & -10.54 \\
\hline Vertical stabilizer right & 115.17 & 284.91 & -2.41 \\
\hline Horizontal stabilizer left & 137.47 & -89.30 & 305.91 \\
\hline Horizontal stabilizer right & 198.17 & -6.72 & 468.83 \\
\hline Total & 527.79 & 415.47 & 761.79 \\
\hline
\end{tabular}

$\alpha=0^{\circ}$, the coefficient $C_{x}$ assumes a value of 0.0052 , while for $\beta=20^{\circ}$ and $\alpha=0^{\circ}$ its value is 0.0009 . The coefficient $C_{x}$ assumes the maximum value for the angle of attack $\alpha=$ $25^{\circ}$ for all considered sideslip angle values.

Figure 9 shows the value of the lateral force coefficient for stabilizers as a function of the angle of attack for the analyzed sideslip angle values. The dependence of the angle of attack on the coefficient $C_{y}$ changes its trend from approximately the constant function to the approximate

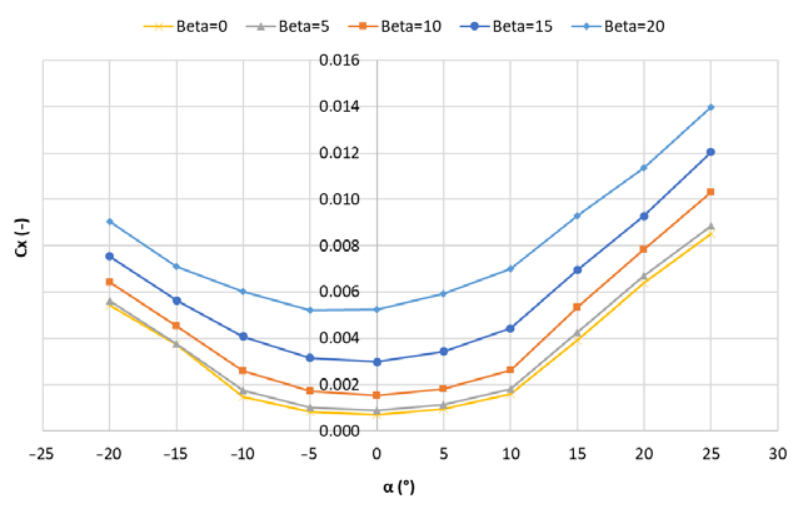

Figure 8. Coefficient of drag force for stabilizers as a function of angle of attack for the analyzed values of sideslip angle

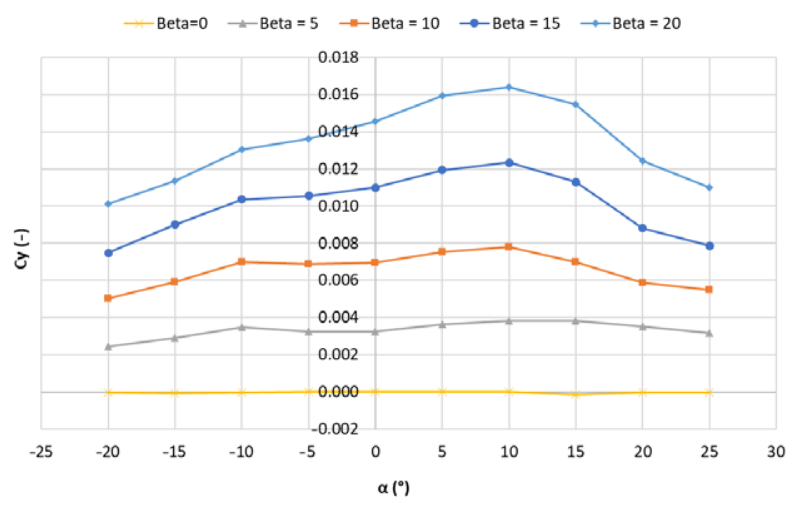

Figure 9. Coefficient of lateral force for stabilizers as a function of angle of attack for the analyzed values of sideslip angle

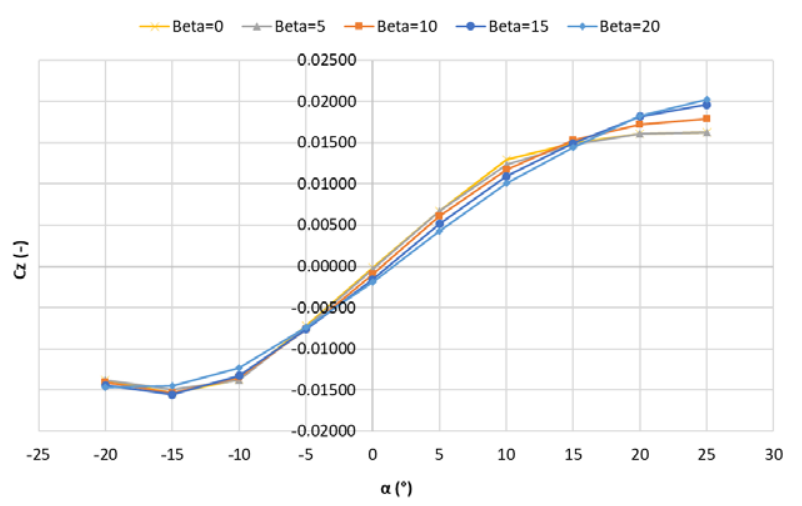

Figure 10. Coefficient of lift force for stabilizers as a function of angle of attack for the analyzed values of sideslip angle 
parabolic function, reaching the extreme (maximum) for a sideslip angle of approximately $10^{\circ}$. The lateral force factor increases with the increase of the sideslip angle reaching the maximum for $\beta=20^{\circ}$. Further increase of the angle of attack results in a decrease in its value. The highest value equal to 0.0164 is obtained for a sideslip angle of $20^{\circ}$ and $\alpha=10^{\circ}$.

Figure 10 shows the value of the lift force coefficient for stabilizers as a function of the angle of attack for the analyzed values of the sideslip angle. The coefficient $C_{z}$, regardless of the sideslip angle, has a similar trace as a function of the angle of attack. A significant difference appears in the range of positive values of angle of attack. The smaller the sideslip angle in this range, the higher the lift force coefficient. This dependence is valid for a certain limit value of an angle of attack equal to about $15^{\circ}$. Above this value, the increase in the sideslip angle results in an increase in the lift force coefficient $C_{z}$. The maximum value equal to 0.0202 is obtained for $\alpha=25^{\circ}$ and $\beta=20^{\circ}$.

Figure 11 shows the contours of pressure at the gyrocopter tail unit in top view for the extreme (biggest) value of the angle of attack $\alpha=25^{\circ}$ and two sideslip angles $\beta=0^{\circ}$ and $\beta=20^{\circ}$. For the sideslip angle $\beta=0^{\circ}$ the symmetry of the flow is visible on the horizontal plane. On the upper surface in the area of the tail boom, a negative pressure in relation to the ambient pressure equal to -406 $\mathrm{Pa}$ is created. This pressure increases to $-278 \mathrm{~Pa}$ in the central part. For the flow of the tail unit at $\beta=20^{\circ}$ a visible asymmetry was obtained which translates into forces acting on individual surfaces. On the right horizontal stabilizer near the tail boom, a negative pressure of $-1500 \mathrm{~Pa}$ (at the leading edge) is generated and its value increases to about $10 \mathrm{~Pa}$ in the trailing edge area. The left horizontal stabilizer is exposed to a lower gradient pressure, which on a large part of the surface is from $-300 \mathrm{~Pa}$ to $-400 \mathrm{~Pa}$.

In the symmetrical case considered in the bottom view (Figure 12), a pressure value of $460 \mathrm{~Pa}$ at the leading edge and around $-87 \mathrm{~Pa}$ at the trailing edge was obtained on the surface of the horizontal plane. For the flow at $\beta=20^{\circ}$, a pressure value of $443 \mathrm{~Pa}$ on the leading edge and around $-79 \mathrm{~Pa}$ at the trailing edge is deposited on the left stabilizer. On the right side it is about $360 \mathrm{~Pa}$ and $60 \mathrm{~Pa}$, respectively.
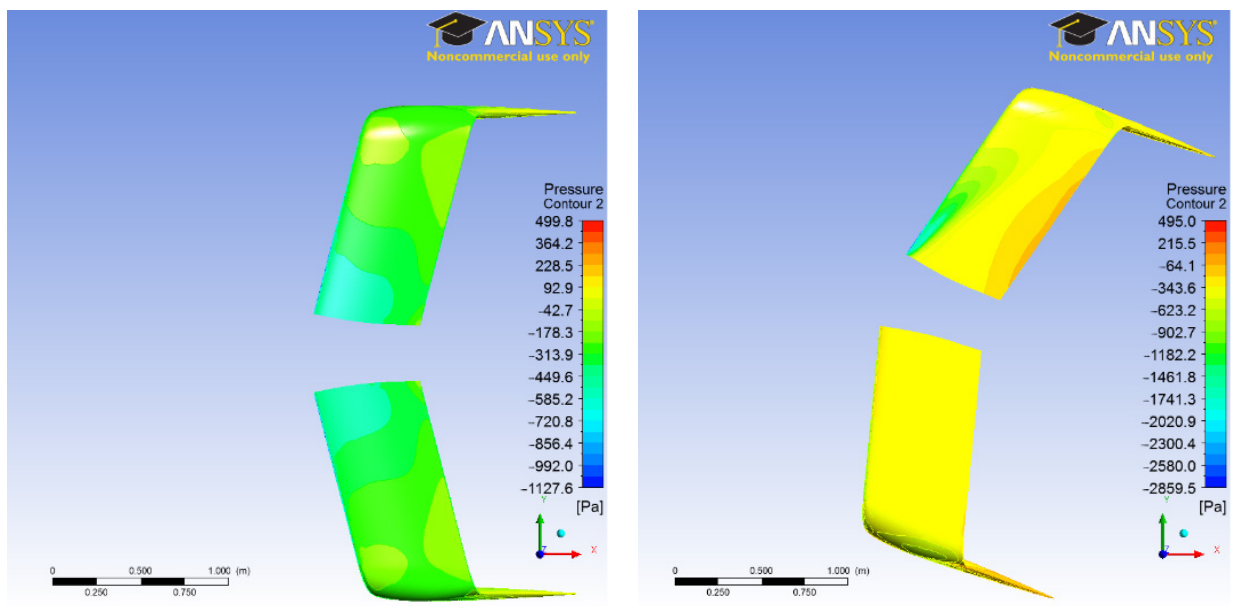

Figure 11. Pressure contours in top view for $\alpha=25^{\circ}, \beta=0^{\circ}$ (left) and $\alpha=25^{\circ}, \beta=20^{\circ}$ (right)
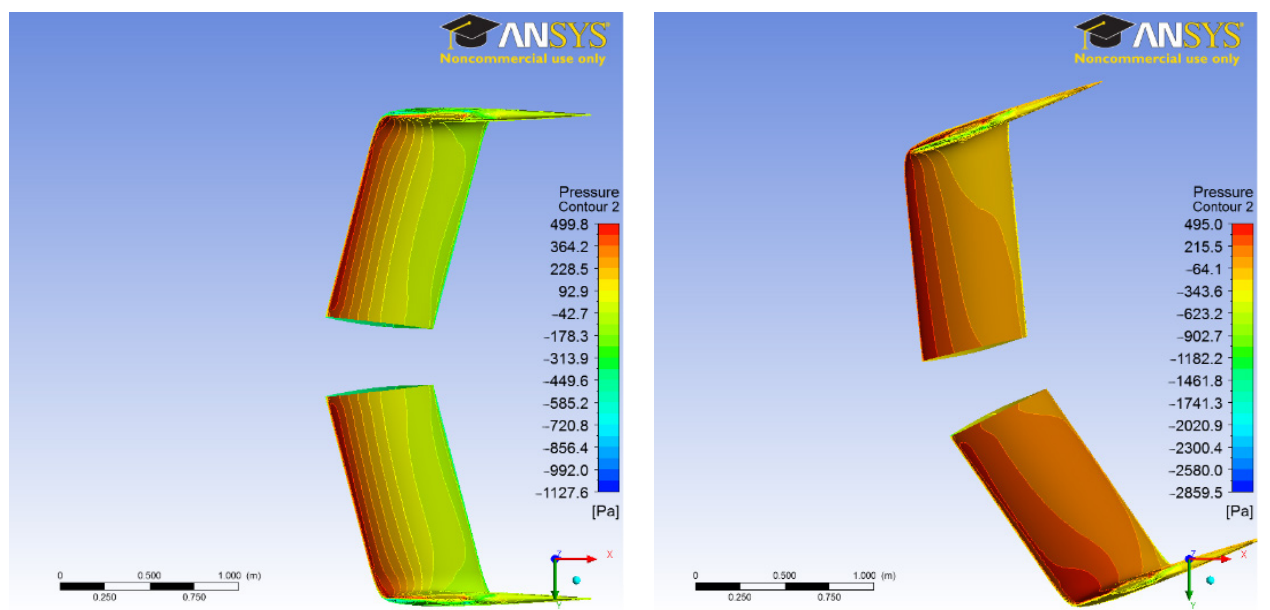

Figure 12. Pressure contours at the gyrocopter stabilizers in a bottom view for $\alpha=25^{\circ}, \beta=0^{\circ}$ (left) and $\alpha=25^{\circ}, \beta=20^{\circ}$ (right) 
In the case of $\alpha=25^{\circ}, \beta=0^{\circ}$ on the inner surface of the vertical stabilizer at the leading edge, a pressure of $440 \mathrm{~Pa}$ and approximately $10 \mathrm{~Pa}$ at the trailing edge were obtained. From the outside, $-530 \mathrm{~Pa}$ was obtained at the leading edge and $-10 \mathrm{~Pa}$ at the trailing edge. In the case of $\alpha=25^{\circ}, \beta=20^{\circ}$ on the inner surface of the left stabilizer at the leading edge, a pressure of $-870 \mathrm{~Pa}$ and approximately $-8 \mathrm{~Pa}$ at the trailing edge. From the outside of the right stabilizer, $266 \mathrm{~Pa}$ was obtained at the leading edge and $-160 \mathrm{~Pa}$ at the trailing edge.

Figure 14 for $\alpha=25^{\circ}, \beta=0^{\circ}$ shows a mirror image of the pressure contour shown in Figure 13. However, for $\alpha=25^{\circ}, \beta=20^{\circ}$ there are significant differences because the external surface of the left stabilizer at the leading edge gives a pressure equal to $440 \mathrm{~Pa}$ and around $27 \mathrm{~Pa}$ at the trailing edge. From the inner side of the vertical stabilizer $450 \mathrm{~Pa}$ was obtained at the leading edge and $-22 \mathrm{~Pa}$ at the trailing edge. In addition, there are differences in the surface areas of the corresponding pressure zones on the inside and outside.
Figure 15 shows the streamlines around the vertical stabilizers in both considered angular positions of the test object. For the version with symmetrical flow $\left(\beta=0^{\circ}\right)$ there is no turbulence and the lines are arranged along the flow, there is a visible deformation of the streamlines down under the tail unit due to the increased pressure field. In the second case, for a large sideslip angle $\left(\beta=20^{\circ}\right)$, on the right vertical stabilizer there is a visible separation of the streamlines and intense vortices on the outside. This is even better illustrated in Figures 15c, 15d and 16 .

Figure 16 shows an iso-surface based on a velocity profile of $15 \mathrm{~m} / \mathrm{s}$. These areas are adequate to the kinetic energy in this area reflecting the increased level of turbulence.

\section{Conclusions}

The paper presents the results of numerical calculations of air flow around the proposed Aduster gyroplane, with particular emphasis on the influence of the sideslip angle on the aerodynamic load of the stabilizers. The change in the angle of the gyrocopter has a significant impact on the aerodynamic forces, act on the tail (stabilizers) and, consequently, on the gen-
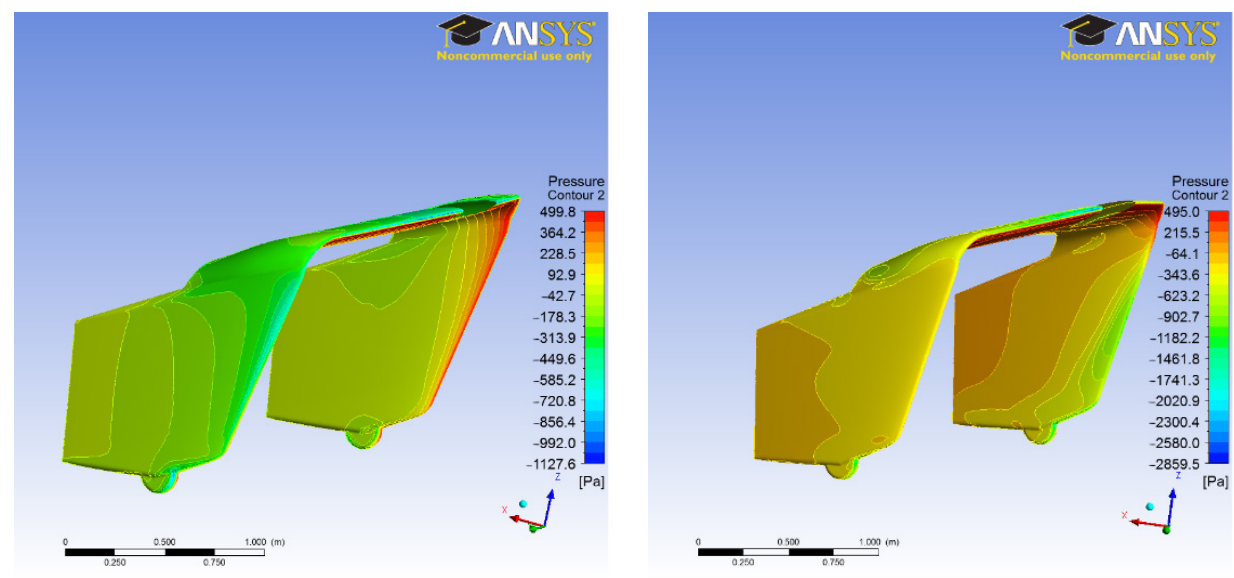

Figure 13. Pressure contours on the gyrocopter vertical stabilizers from the side opposite to the $y$ axis direction for $\alpha=25^{\circ}, \beta=0^{\circ}$ (left) and $\alpha=25^{\circ}, \beta=20^{\circ}$ (right)
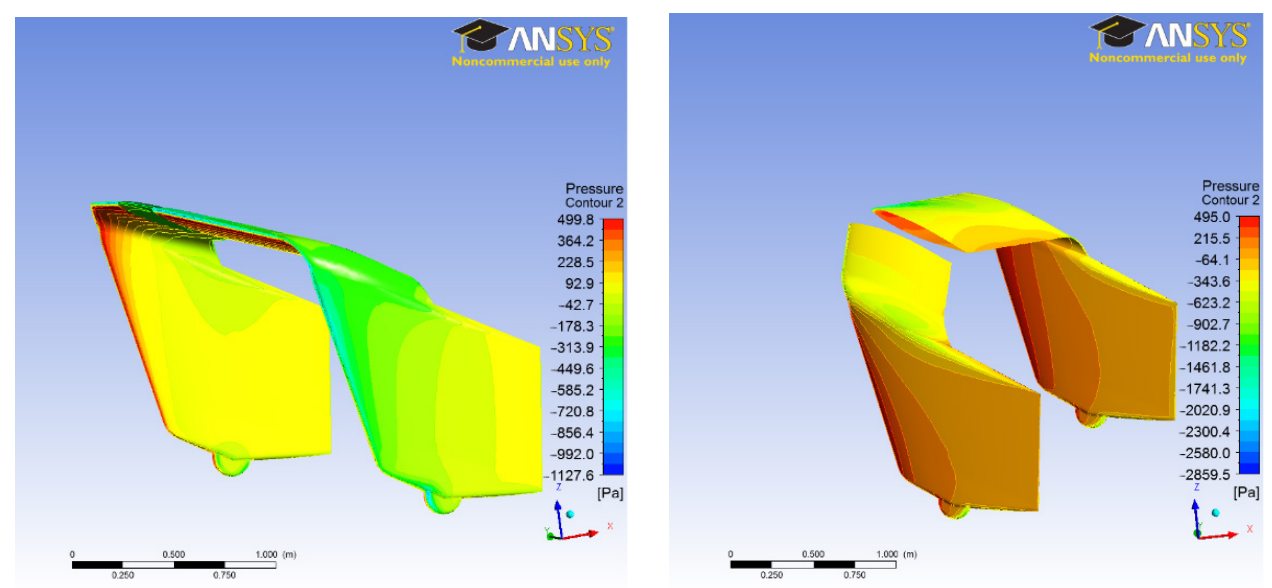

Figure 14. Pressure contours on the gyrocopter vertical stabilizers from the side consistent with the $y$ axis for $\alpha=25^{\circ}, \beta=0^{\circ}$ (left) and $\alpha=25^{\circ}, \beta=20^{\circ}$ (right) 


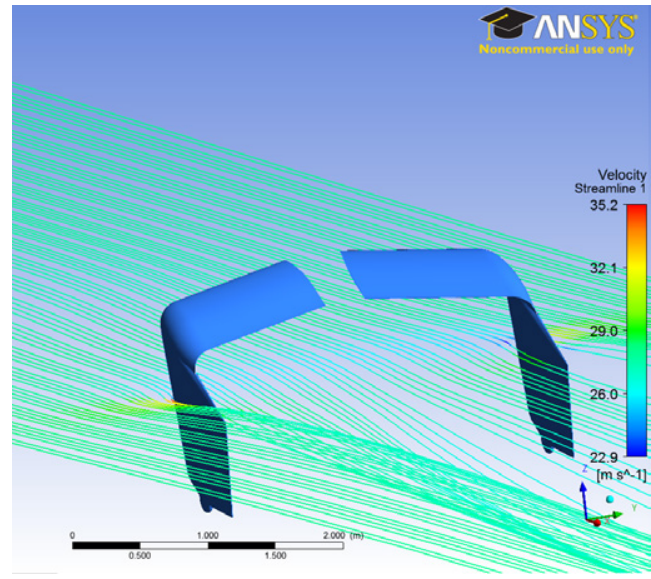

a)

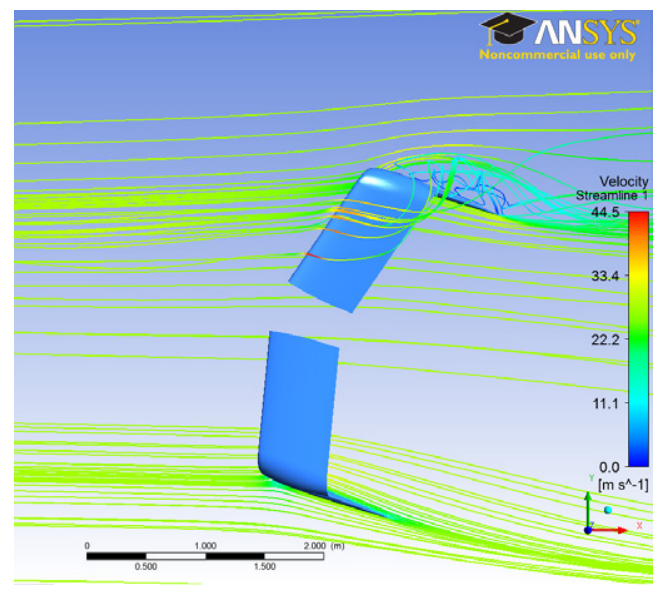

c)

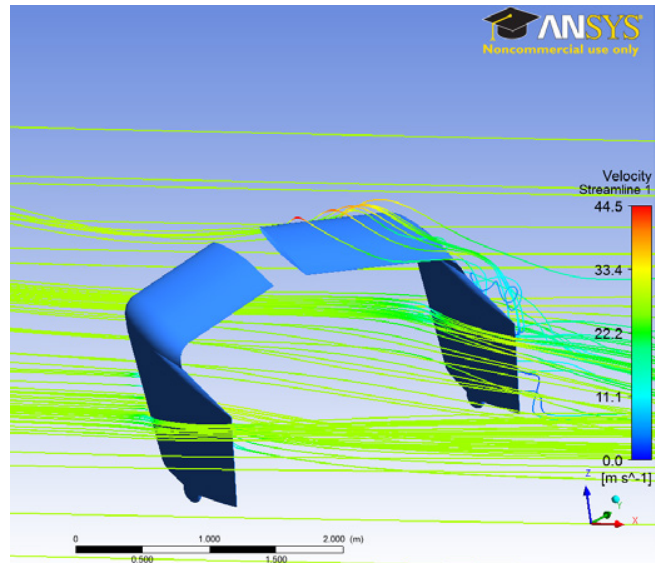

b)

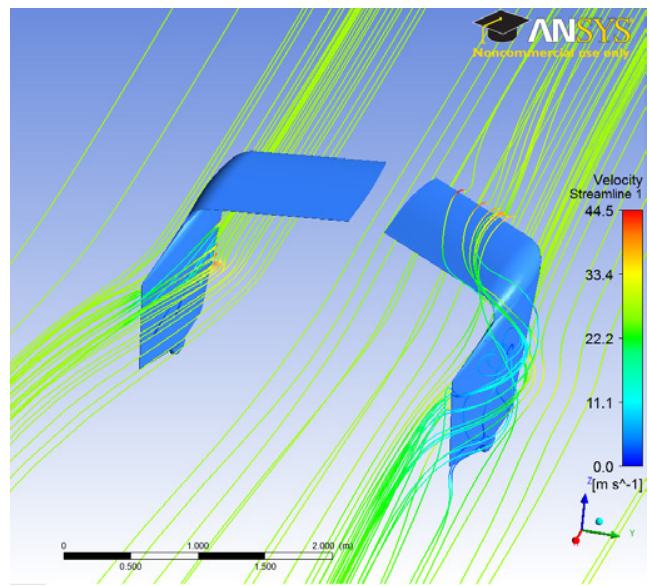

d)

Figure 15. View of the streamlines flowing around the vertical stabilizers: a) for $\alpha=25^{\circ}$ and $\beta=0^{\circ}$ and b), c), d) for $\alpha=25^{\circ}$ and $\beta=20^{\circ}$

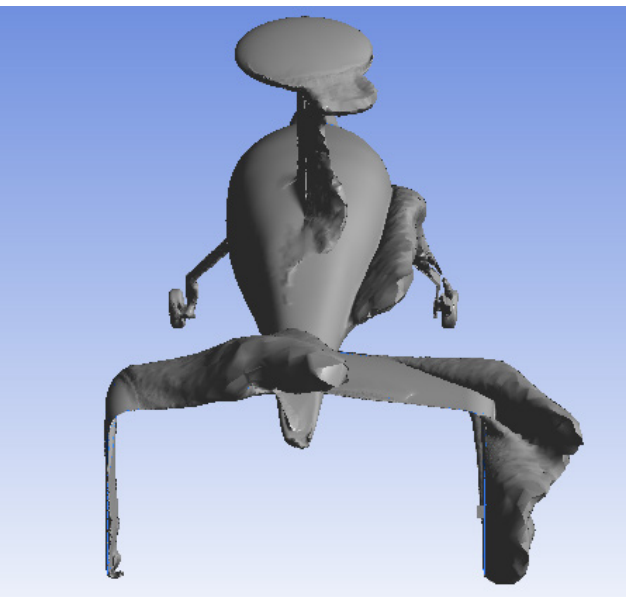

Figure 16. Iso-surface view for a speed equal to $15 \mathrm{~m} / \mathrm{s}$

eral characteristics of the entire gyroplane. The calculations were carried out for rake angles in the range $-20^{\circ}$ to $+25^{\circ}$, every $5^{\circ}$, and the sideslip angle were changed in the range of $0^{\circ}$ to $+20^{\circ}$, every $5^{\circ}$. First of all, one should pay attention to the fact that at one of the extreme angular positions of the object, i.e. $\alpha=25^{\circ}$ and $\beta=0^{\circ}$, the symmetry of the stabilizers loads with aerodynamic forces was obtained. The right and the left vertical stabilizer is subjected to a relatively small drag force $P_{x}$ equal to $3.72 \mathrm{~N}$ and $3.52 \mathrm{~N}$, while lateral force and lifting force are respectively $P_{y}=131.44 \mathrm{~N}$ and $-13.63 \mathrm{~N}, P_{z}=$ $-0.72 \mathrm{~N}$ and $-0.78 \mathrm{~N}$. On the horizontal stabilizer, the drag is relatively high and amounts to $156.92-157.31 \mathrm{~N}$. Lifting force, on the other hand, is $306,99-307,36 \mathrm{~N}$.

The difference between the left and right sides increases with the sideslip angle and for the extreme angle $\beta=20^{\circ}$ visible differences in the forces acting on the left and right stabilizer were obtained. For the same angle of attack $\left(\alpha=25^{\circ}\right)$ up to $53 \%$ difference between the lift force on the left $\left(P_{Z}=305.91 \mathrm{~N}\right)$ and right $\left(P_{Z}=468.83 \mathrm{~N}\right)$ horizontal stabilizer and the right one was obtained.

All this affects the aerodynamic moments acting on the whole research object, especially on the roll moment $M_{x}$, which on the left horizontal stabilizer is $-560.25 \mathrm{Nm}$, and on the right only $-16.79 \mathrm{Nm}$.

The calculations made are part of the work on the new gyroplane. In the future, they will be validated by conducting tests in the wind tunnel. Based on the obtained results, it is possible to calculate the strength of the gyrocopter structure - especially the tail boom that transfers all loads from the tail unit. 


\section{Funding}

This work was supported by the Polish National Centre for Research and Development under Grant Agreement No. POIR.01.01.01-00-0056/16.

\section{Author contributions}

Zbigniew Czyż: acquisition of data, conception and design of the work, interpretation of data, revising for important intellectual content.

Paweł Karpiński: acquisition of data, analysis and interpretation of data, drafting the article.

\section{Disclosure statement}

The authors declare that no conflict of interest, competing financial, professional, or personal interests from other parties.

\section{References}

Anh Vu, N., Lee, Y. J., Lee, J. W., Kim, S., \& Jae Chung, I. (2011). Configuration design and optimisation study of a compound gyroplane. Aircraft Engineering and Aerospace Technology, 83(6), 420-428. https://doi.org/10.1108/00022661111173298

Cheng, X., Xin, R., Bao, G., Luo, D., Guo, Z., \& Wu, L. (2016, August). Parameters identification of gyroplane longitudinal/lateral model from flight test. Proceedings of 2016 IEEE Chinese Guidance, Navigation and Control Conference (pp. 300-305). IEEE. Nanjing, China. https://doi.org/10.1109/CGNCC.2016.7828801

Czyż, Z., Karpiński, P., Łusiak, T., \& Szczepanik, T. (2017). Numerical analysis of the influence of particular autogyro parts on the aerodynamic forces. In ITM Web of Conferences, 15, 07008. EDP Sciences. Paper presented at II International Conference of Computational Methods in Engineering Science (CMES'17). Lublin, Poland.

https://doi.org/10.1051/itmconf/20171507008

Czyż, Z., Łusiak, T., Karpiński, P., \& Czarnigowski, J. (2018, October). Numerical investigation of the gyroplane longitudinal static stability for the selected stabilizer angles. Journal of Physics: Conference Series, 1101(1), 012003. https://doi.org/10.1088/1742-6596/1101/1/012003

Della Vecchia, P., Nicolosi, F., \& Ciliberti, D. (2015). Aircraft directional stability prediction method by CFD (p. 2255). Paper presented at the 33rd AIAA Applied Aerodynamics Conference. Dallas, USA. https://doi.org/10.2514/6.2015-2255

Dziubiński, A., Jaśkowski, P., \& Seredyn, T. (2016). CFD analysis of agricultural aircraft aerodynamic characteristics. Prace Instytutu Lotnictwa. https://doi.org/10.5604/05096669.1229486

Figat, M. (2017). Aerodynamics analysis of the main rotor influence on the static stability of the gyroplane. Aircraft Engineering and Aerospace Technology, 89(5), 663-670. https://doi.org/10.1108/AEAT-01-2017-0047

Green, B. E., \& Findlay, D. (2016). CFD Analysis of the F/A-18E Super Hornet during Aircraft-Carrier Landing High-Lift Aerodynamic Conditions. In 54th AIAA Aerospace Sciences Meeting (p. 1768). https://doi.org/10.2514/6.2016-1768

Houston, S. S. (1996). Longitudinal stability of gyroplanes. The Aeronautical Journal, 100(991), 1-6.

https://doi.org/10.1017/S0001924000027196
Houston, S. S. (1998). Identification of autogyro longitudinal stability and control characteristics. Journal of Guidance, Control, and Dynamics, 21(3), 391-399. https://doi.org/10.2514/2.4271

Houston, S. S. (1998). Identification of gyroplane lateral/directional stability and control characteristics from flight test. Proceedings of the Institution of Mechanical Engineers, Part G: Journal of Aerospace Engineering, 212(4), 271-285. https://doi.org/10.1243/0954410981532432

Houston, S. S. (2011). Light gyroplane empennage design considerations. The Aeronautical Journal, 115(1170), 505-511. https://doi.org/10.1017/S000192400000614X

Houston, S., \& Thomson, D. (2017). On the modelling of gyroplane flight dynamics. Progress in Aerospace Sciences, 88, 43-58. https://doi.org/10.1016/j.paerosci.2016.11.001

Jensen, D. (2001, October). Un-manned autogyro for cinematography and reconnaissance. In 1st AIAA, Aircraft, Technology Integration, and Operations Forum (p. 5228), Los Angeles, USA. https://doi.org/10.2514/6.2001-5228

Krzysiak, A. (2017). Wind tunnel tests of quad-rotor autogyro model. Journal of KONES, 24. https://doi.org/10.5604/01.3001.0010.2819

Leishman, G. J. (2006). Principles of helicopter aerodynamics. Cambridge University Press.

Lin, Q., Cai, Z., \& Wang, Y. (2014, August). Design, model and attitude control of a model-scaled gyroplane. In Proceedings of 2014 IEEE Chinese Guidance, Navigation and Control Conference, IEEE (pp. 1282-1287). Yantai, China. https://doi.org/10.1109/CGNCC.2014.7007385

Ma, T., Hao, S., Xue, P., Li, G., \& Gan, W. (2015, August). A fast method of aerodynamic computation for compound gyroplane. In 2015 3rd International Conference on Mechanical Engineering and Intelligent Systems. Atlantis Press. https://doi.org/10.2991/icmeis-15.2015.20

Ma, Y., Huang, B., Xiang, C., Wang, W., \& Huang, N. (2015, June). Forward flight attitude control of unmanned small-scaled gyroplane based on $\mu$-synthesis. In 2015 International Conference on Unmanned Aircraft Systems (ICUAS), IEEE (pp. 1338-1345). Denver, USA. https://doi.org/10.1109/ICUAS.2015.7152428

Patel, K. S., Patel, S. B., Patel, U. B., \& Ahuja, A. P. (2014). CFD Analysis of an Aerofoil. International Journal of Engineering Research, 3(3), 154-158. https://doi.org/10.17950/ijer/v3s3/305

Stalewski, W. (2017). Improvement and optimisation of gyroplane performance. Prace Instytutu Lotnictwa.

Wang, J. C., \& Li, J. B. (2014). Effects of Wing on Autogyro Longitudinal Stability [J]. Acta Aeronautica ET Astronautica Sinica, 35(1), 151-160. http://hkxb.buaa.edu.cn/EN/Y2014/V35/I1/151

Xiang, C., Wang, X., Ma, Y., \& Wang, Y. (2014, August). Modeling and modal responses analysis of an unmanned small-scaled gyroplane. In Proceedings of 2014 IEEE Chinese Guidance, Navigation and Control Conference IEEE (pp. 262-268). Yantai, China. https://doi.org/10.1109/CGNCC.2014.7007243

Xiang, C., Yang, X., Xu, B., Han, H., \& Liu, L. (2015, June). Numerical simulation of unsteady flow past autorotating rotor in gyroplane level flight. In 2015 International Conference on Unmanned Aircraft Systems (ICUAS), IEEE (pp. 1178-1187). Denver, USA. https://doi.org/10.1109/ICUAS.2015.7152410

Zhang, D., Cai, Z., Lin, Q., Huang, D., \& Yang, J. (2014, August). Design of longitudinal stability controller for unmanned gyroplane based on fuzzy sliding mode theory. In Proceedings of 2014 IEEE Chinese Guidance, Navigation and Control Conference, IEEE (pp. 2088-2093). Yantai, China. https://doi.org/10.1109/CGNCC.2014.7007499 


\section{Notations}

Variables and functions

$\alpha$ - angle of attack;

$\beta$ - sideslip angle;

$P_{x}-$ drag force;

$P_{y}$ - lateral force;

$P_{z}-$ lift force;

$C_{x}$ - drag force coefficient;

$C_{y}$ - lateral force coefficient;

$C_{z}$ - lift force coefficient;

$R$ - rotor radius;

$\rho$ - air density;

$v$ - air velocity.

\section{Abbreviations}

SST - Shear Stress Transport

CFD - Computational Fluid Dynamics

PIV - Particle Image Velocimetry

FMAC - Fast Method of Aerodynamic Computation 